\title{
Differential Equations E-course in Nomotex DLS
}

\author{
Yury I. Dimitrienko ${ }^{1}$, Tatiana L. Anisova ${ }^{1 *}$, Anna A. Smekhnova ${ }^{1}$, and Alexander V. Alesin ${ }^{1}$ \\ ${ }^{1}$ Bauman Moscow State Technical University, 2nd Baumanskaya str., 5/1, 105005, Moscow, Russia
}

\begin{abstract}
The electronic course "Differential Equations" in the Digital Learning System (DLS) NOMOTEX is developed and used for the mathematical training of future engineers. The artcle presents the content and features of the development of the module, as well as the methodology for conducting classroom studies in a digital educational environment. In the Nomotex DLS, the e-course is presented as a neural network structure of knowledge - a tree. The content of the e-course is divided into chapters and paragraphs. Within a paragraph, the content is presented in the form of units of knowledge called quanta. The structure of quanta is described in detail, examples are given. The peculiarity of the described methodology is the preservation of traditional forms of education - lectures and seminars with the use of a digital educational environment together. At the same time, in the learning process using the NOMOTEX DLS, traditional classroom lessons change significantly. The features of conducting lectures and seminars, measures for monitoring students' knowledge are described. The Digital Learning System NOMOTEX allows you to implement various courses, forming the content of lectures and seminars from the existing knowledge bank. E-course, usually a part of the course "Integrals and Differential Equations", read to future engineers in the spring semester of the first year at the Bauman Moscow State Technical University.
\end{abstract}

\section{Introduction}

Latterly, the process of informatization of education is gaining momentum. This process determines the creation of new technologies and methodological systems of teaching aimed at improving the intellectual potential of the student, at the formation of the ability to independently acquire knowledge, to carry out educational, research activities, as well as various types of independent activities [1,2,3]. All this requires the improvement of the methodology for selecting the content, means, methods and organizational forms of training. In full measure, all these aspects apply to the mathematical training of future engineers.

The results of the studies described in the works [4,5,6], show a positive relationship between the use of Internet learning technologies and student involvement in the learning process, as well as the results of self-assessment of learning. The authors analyze the latest advances in the application of digital technologies in mathematics education - mobile

\footnotetext{
*Corresponding author: bolashova@ mail.ru
} 
technologies, massive open online courses, digital libraries, mixed studying using digital technologies.

\section{Material and methods}

The "Differential Equations" course in NOMOTEX DLS was started to develop and introduced into the educational process in the 2018-2019 academic year. During the spring semester, it was tested at the Faculty of Power Engineering and the Aerospace Faculty of the Bauman Moscow State Technical University.

\section{Course structure}

The course is presented in DLS NOMOTEX in the form of a neural network structure of knowledge (Fig. 1).

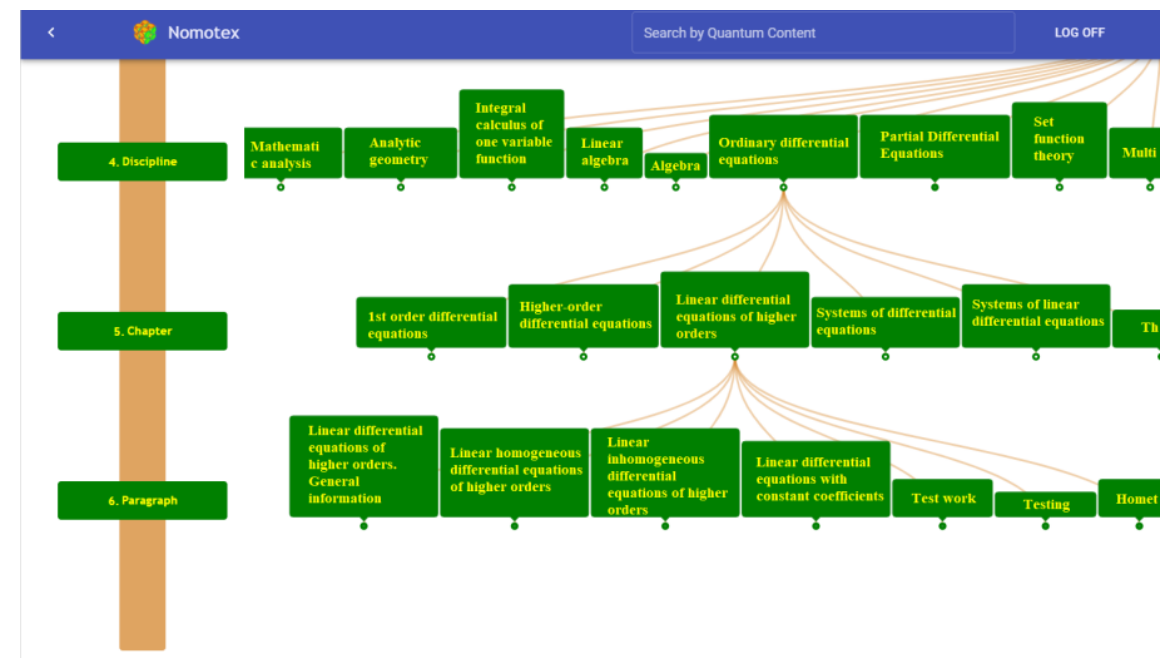

Fig. 1. Neural network knowledge structure (Tree).

The course content is traditionally divided into chapters and paragraphs.

Chapter 1. Differential equations of the first order.

General information about differential equations.

Ordinary differential equations of the first order.

Chapter 2. Differential equations of higher orders.

2.1. Equations admitting lowering of order.

Chapter 3. Linear differential equations of higher orders.

3.1. Linear differential equations of higher orders. General information.

3.2. Linear homogeneous differential equations of higher orders.

3.3. Linear inhomogeneous differential equations of higher orders.

3.4. Linear differential equations with constant coefficients.

Chapter 4. Systems of differential equations.

4.1. Normal systems of differential equations.

Chapter 5. Systems of linear differential equations.

5.1. Systems of linear homogeneous differential equations.

5.2. Systems of linear inhomogeneous differential equations.

5.3. Systems of linear differential equations with constant coefficients. 
The content inside every paragraph is presented in the form of quantum - units of knowledge [7,8] (Fig. 2).
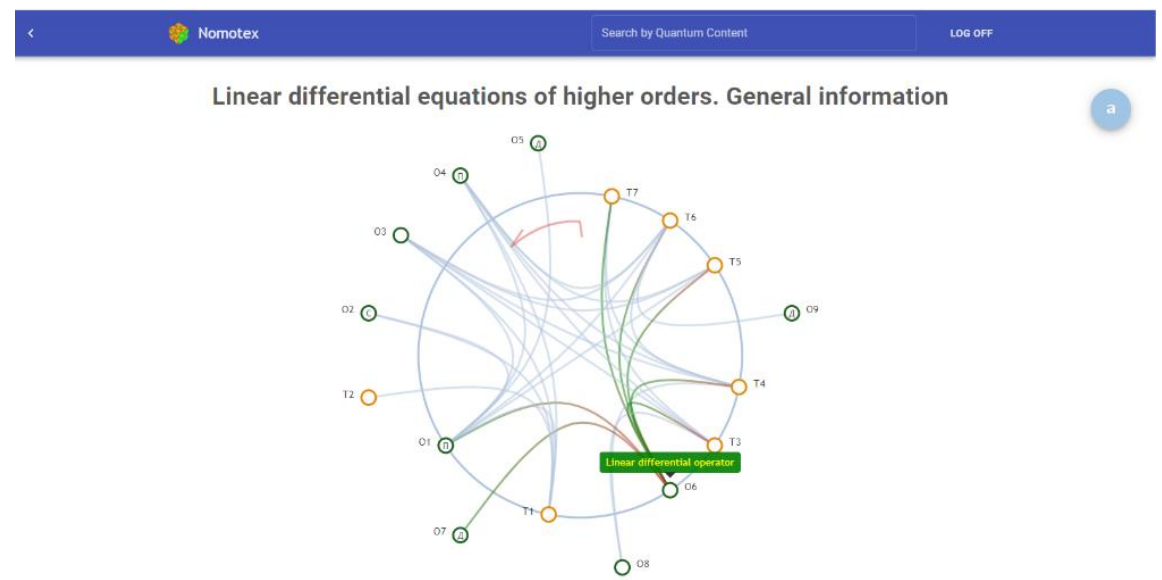

Fig. 2. Contents of the paragraph.

The quantum contain definitions (D), theorems (T), properties (P) and methods for solving problems - the quantum "construction" (C). All quantums of the current paragraph are located on a circle. The quantums from other chapters and courses, related to the content of this paragraph, are located outside the circle. The connections between the presented quantum are shown.

\section{Course structure}

Each quantum is graphically represented as a "traffic light" and consists of three windows in green, yellow and red (Fig. 3). 


\section{Theorem on the structure of the general solution of a linear homogeneous differential equation of the nth order $(T)$}

\section{Theorem and its connections}
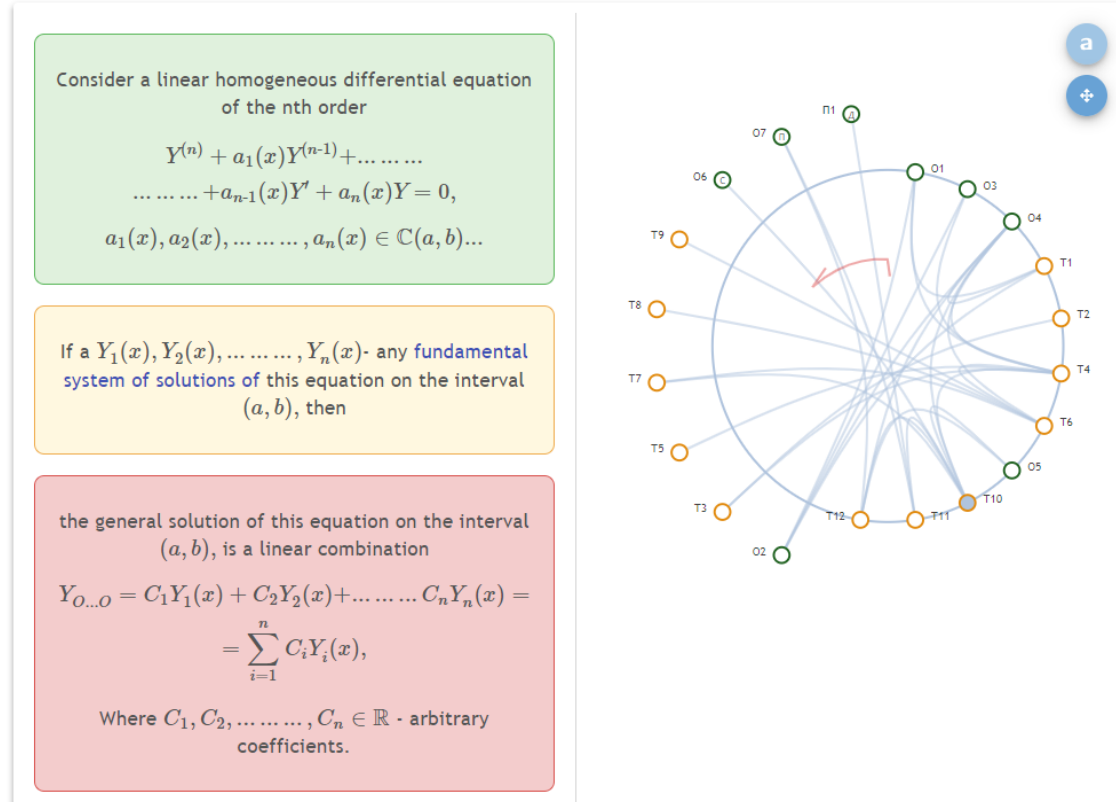

Fig. 3. Content of quantum.

The definition of a mathematical concept divided into 3 parts. The first two windows contain a set of conditions necessary and sufficient for the selection of classes of objects belonging to this concept, and the red one - the name of the concept.

\subsection{Example 1. Quantum "Fundamental system of solutions of a linear homogeneous differential equation"}

Consider a linear homogeneous differential equation of the $n$-th order

$$
\begin{gathered}
y^{(n)}+a_{1}(x) y^{(n-1)}+\ldots+a_{n-1}(x) y^{\prime}+a_{n}(x) y=0, \\
a_{1}(x), a_{2}(x), \ldots, a_{n}(x) \in \Im(a, b) .
\end{gathered}
$$

The set of any $\mathrm{n}$ linearly independent on the interval $(a, b)$ solutions $y_{1}(x), y_{2}(x), \ldots, y_{n}(x)$ to this equations is called the fundamental system of solutions (FSS) on the interval $(a, b)$

The theorems are formulated not in a categorical, but in a conditional form. The first two windows contain the condition of the theorem, the third - its conclusion. 


\subsection{Example 2. Quantum "Theorem on the structure of the general solution of a linear homogeneous differential equation of the $n$-th order" (T)}

Consider a linear homogeneous differential equation of the $n$-th order

$$
\begin{gathered}
y^{(n)}+a_{1}(x) y^{(n-1)}+\ldots+a_{n-1}(x) y^{\prime}+a_{n}(x) y=0, \\
a_{1}(x), a_{2}(x), \ldots, a_{n}(x) \in \Im(a, b) .
\end{gathered}
$$

If $y_{1}(x), y_{2}(x), \ldots, y_{n}(x)$ is some fundamental system of solutions of this equation on an $(a, b)$ interval, then the general solution of this equation on the interval $(a, b)$ is the linear combination

$$
y_{o .0}=C_{1} y_{1}(x)+C_{2} y_{2}(x)+\ldots+C_{n} y_{n}(x)=\sum_{i=1}^{n} C_{i} y_{i}(x)
$$

where $C_{1}, C_{2}, \ldots, C_{n} \in \mathbb{R}$ are arbitrary coefficients.

Some windows contain proofs of theorems, corollaries, remarks, geometric illustrations, mathematical examples, and problems matched to a studied quantum.

We note a convenient system of links located in the content of the quantum, that allows you to see the necessary information from the entire presented knowledge base in the popup windows, and the possibility of a step-by-step presentation of the material presented in the quantum.

The uniqueness of the DLS NOMOTEX is that it allows the possibility of conducting all types of classroom and independent work with students.

The cornerstone issue in the discussion of the use of digital technologies in mathematics education is the issue of preserving the classical lecture in existing realities or transforming it into any other forms $[9,10,11,12]$.

In the process of teaching mathematical disciplines in the DLS NOMOTEX, the lecture significantly changes. Reading lectures using DLS NOMOTEX is accompanied by showing on an interactive whiteboard the necessary theoretical material collected in a unified knowledge base and highlighted in a separate lecture using the option "implementation of neural network educational programs".

Students have the opportunity to use their own laptops, tablets in the classroom, to work with the mobile version of the NOMOTEX DLS and, which is very important, continue the work they started at home.

In addition, the teacher has the opportunity to use the blackboard and chalk during the lecture.

Seminars are also held in specialized classrooms. DLS NOMOTEX provides algorithms for solving standard problems. Each seminar is equipped with a large number of analyzed examples and tasks for independent work (Fig. 4). 


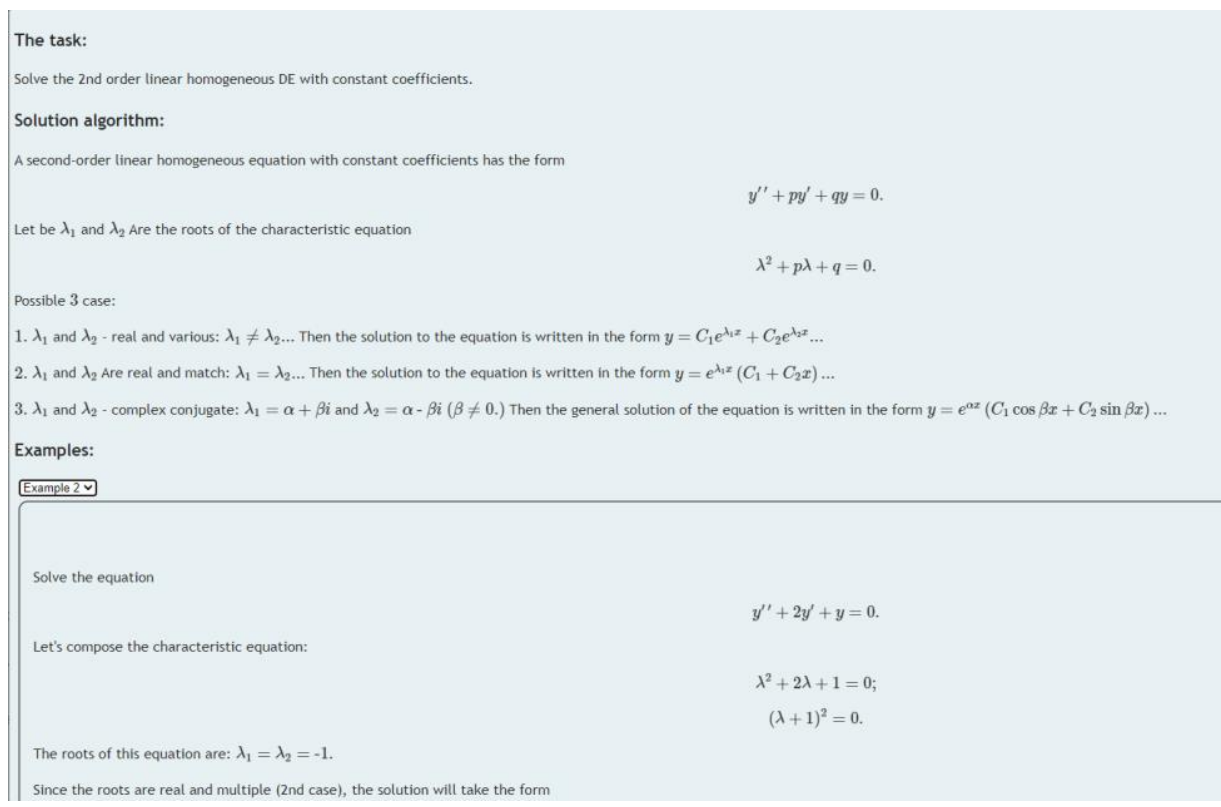

Fig. 4. An example of a problem for a seminar.

Testing activities are also carried out in the DLS. Issuance of papers for a control event, check of completed work, rating of students are available to the teacher through the "personal account" service.

The differential equations module provides the following test activities: control work (differential equations of the first order, equations allowing lowering the order), homework (equations allowing lowering the order, linear differential equations of higher orders), milestone control (theoretical test, linear differential equations of higher orders, systems of linear differential equations).

As is known, when designing automated control tools for mathematical knowledge and skills, it is very difficult to check the correctness of the answers.

In those problems that require finding a general solution to an ordinary differential equation, in the DLS Nomotech the answer can be entered in the form or in the form of a function given implicitly (Fig. 5).

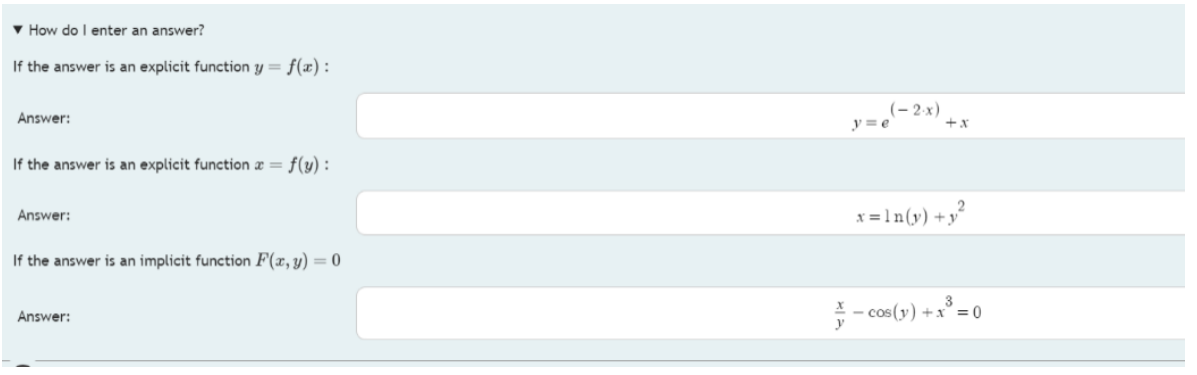

Fig. 5. An example of a problem for a seminar.

After the answer is entered the system automatically checks it using the following algorithm:

1. Calculate the derivative of a function (for an equation of the 1 st order), several derivatives (for equations of a higher order). Well-known formulas are used to calculate the derivative of the inverse function and the derivative given implicitly in this case. 
2. The resulting function and its derivatives are substituted into the original equation and the fact that the original equation has become an identity is verified. This check is performed in several stages. The system contains 15 algorithms to simplify the expression (this number is constantly growing in the process of improving the system).

3. When solving the Cauchy problem, a check is added for the fulfillment of the initial conditions by means of their direct substitution into the resulting function and its derivatives.

Theoretical tests contain questions of the following types

1. Choose the correct statement from the proposed ones.

2. Select a match.

3. Choose the correct condition for a certain theorem.

Note that during the final certification, a theoretical question with proof is added to the test tasks, which the student answers verbally.

DLS NOMOTEX allows to implement various courses, forming the content of lectures and seminars from the existing knowledge bank.

For example, traditionally in the spring semester future engineers learn the course "Integrals and Differential Equations", consisting of two corresponding modules.

\section{Conclusion}

The training module "Differential Equations" in the Digital Learning System NOMOTEX is developed and used for the mathematical training of future engineers at the Bauman Moscow State Technical University. The paper shows the features of the selection of the content of the studied material and methods of conducting classroom studies using a digital educational environment. The fact to emphasize is DLS NOMOTEX makes it possible both to preserve traditional forms of education - lectures and seminars, and to use various blended forms of learning. Students have an uninterrupted opportunity to continue the work begun in the classroom and study the necessary material on their own. With the help of an automated knowledge testing system, the process of monitoring students' activities and assessing their achievements is simplified and improved.

Training using the presented digital educational environment for two years has shown its effectiveness, including during the forced full transition to distance learning. $90 \%$ of students received positive marks on the basis of the intermediate control (exam) in the spring semester of 2020 .

\section{References}

1. V.I. Mayorova, D.A. Grishko, V.V. Leonov, "Vivid mathematics" as a general vector of multidisciplinary STEM education for future aerospace engineers, Acta Astronautica, 178, pp. 72-80 (2021)

2. V.A. Shakhnov, A.A. Glushko, E.V. Rezchikova, L.A. Zinchenko, V.V. Terekhov, V.V. Makarchuk, TCAD and Cognitive Visualization in Electronic Engineering Education: BMSTU Case Study (2020), 2020 5th International Conference on Information Technologies in Engineering Education, Inforino 2020 - Proceedings (2020)

3. L.V. Juravleva, V.A. Shakhnov, A.I. Vlasov, Adaptation of professional engineering training to the challenges of modern digital production (2020), Intelligent Systems and Computing, 1134 AISC, pp. 623-633 (2020) 
4. P.S.D. Chen, A.D. Lambert \& K.R. Guidry, Engaging online learners: The impact of Web-based learning technology on college student engagement, Computers \& Education, 54(4), pp. 1222-1232 (2010)

5. C. Brooks, G. Erickson, J. Greer \& C. Gutwin, Modelling and quantifying the behaviours of students in lecture capture environments, Computers \& Education, 75, pp. 282-292 (2014)

6. M.C. Borba, P. Askar, J. Engelbrecht, G. Gadanidis, S. Llinares \& M.S. Aguilar, Blended learning, e-learning and mobile learning in mathematics education, ZDM, 48(5), pp. 589-610 (2016)

7. Yu.I. Dimitrienko, E.A. Gubareva, Novaya tekhnologiya matenaticheskoj podgotovki inzhenernykh kadrov, osnovannaya na nejrosetevoj modeli znanij [New technology for mathematical training of engineering personnel based on the neural network model of knowledge], Innovatsii v obrazovznii [Innovation in education], No. 11, pp. 129-140 (2017)

8. Yu.I. Dimitrienko, E.A. Gubareva, Novaya nauchno-metodicheskaya model matenaticheskoj podgotovki inzhenerov [New scientific and methodological model of mathematical training of engineers], Mezhdunarodnyj zhurnal ehksperimantalnogo obrazovaniya [International Journal of Experimental], No. 11, pp. 5-10 (2017)

9. D. Pritchard, Where learning starts? A framework for thinking about lectures in university mathematics, International Journal of Mathematical Education in Science and Technology, 41(5), pp. 609-623 (2010)

10. C. Yoon \& J. Sneddon, Student perceptions of effective use of tablet PC recorded lectures in undergraduate mathematics courses, International Journal of Mathematical Education in Science and Technology, 42(4), pp. 425-445 (2011)

11. C. Yoon, G. Oates \& J. Sneddon, Undergraduate mathematics students' reasons for attending live lectures when recordings are available, International Journal of Mathematical Education in Science and Technology, 45(2), pp. 227-240 (2014)

12. E. Howard, M. Meehan \& A. Parnell, Live lectures or online videos: students' resource choices in a first-year university mathematics module, International Journal of Mathematical Education in Science and Technology, 49(4), pp. 530-553 (2018) 